\title{
MICROBIAL INOCULANTS MODULATE PHYSIOLOGICAL BEHAVIOUR OF TROYER CITRANGE UNDER DROUGHT STRESS
}

\author{
Prananath Barman ${ }^{1 *}$ and Sanjay Kumar Singh \\ Indian Agricultural Research Institute, New Delhi-110 012, India \\ Keywords: Glomus intraradices, Leaf enzyme activity, Microbial biomass, Carbon
}

\begin{abstract}
A study was undertaken with Troyer citrange (Citrus sinensis $\times$ Poncirus trifoliata), the rootstock of citrus, to elucidate the interaction effects of arbuscular mycorrhizal fungi and plant-growth-promoting bacteria on plant physiology under both ample watered and water stress conditions. The result exhibited significant influence of Glomus intraradices and phosphorus solubilising bacteria (PSB) (mixture of Bacillus subtilis and $B$. megatherium) on plant growth due to root-fungus-bacteria interaction leading to reduced accumulation of reactive oxygen species, production of antioxidant metabolites, higher anti-scavenging enzymes and higher acquisition of plant nutrients, besides enhancing rhizosphere microbial activity. Thus, Troyer citrange could be co-inoculated with $G$. intraradices and PSB during propagation for healthy growth of the seedlings thereby pre-ponding the budding and subsequent establishment of composite plants under field conditions.
\end{abstract}

\section{Introduction}

The two major global challenges afflicting world population are hunger and nutritional insecurity. The increasing demand can be met by exploiting the marginal, saline and drought prone areas for cultivation of fruit crops, thereby offering unique advantage to food and nutritional security. Citrus species, though grown in areas between latitudes of $40^{\circ} \mathrm{N}$ and $40^{\circ} \mathrm{S}$, however, poor plant growth due to deficits of water and nutrients, cause economic losses in orchards in arid and semi-arid regions of tropical and sub-tropical areas of the world. The environmental stress may impair electron transport system leading to the formation of activated oxygen compounds causing a cascade of damaging effect in chloroplast. Ubiquitous arbuscular mycorrhizal (AM) fungi and plant-growth-promoting bacteria can interact in specific ways to influence their relationship with and their effect on plant growth (Galleguillos et al. 2000). Citrus has a few and short root hairs in the field and is highly dependent on arbuscular mycorrhizae. Therefore, the study was undertaken on a citrus rootstock, Troyer citrange to determine the effectiveness of AM fungi and bacteria under drought stress.

\section{Materials and Methods}

This study was conducted at Indian Agricultural Research Institute (IARI), New Delhi. Climate was categorized as semi-arid, subtropical with hot dry summer and cold winter.

The starter culture of AM fungus Glomus intraradices was multiplied in maize in plastic pot $(12 \mathrm{~cm} \times 20 \mathrm{~cm})$ filled with a mixture of soil, sand and farm-yard manure $(2: 2: 1)$ which was autoclaved. The inoculum was sealed in a polythene packet consisting of freshly collected rhizosphere soil and AM fungal spores along with hyphae, arbuscules, vesicles and root segments of maize plant. Providencia sp., strain AW5, was isolated from the wheat rhizosphere (Rana et al. 2011). Inoculum of this bacterial strain was prepared by growing in nutrient broth at $28 \pm 1^{\circ} \mathrm{C}$ for

*Author for correspondence: <neelmoy.horticulture@gmail.com>. ${ }^{1}$ Division of Crop Production, ICARCentral Institute for Subtropical Horticulture, Rehmankhera, Kakori, Lucknow-226 101, Uttar Pradesh. 
$48 \mathrm{hrs}$ at $100 \mathrm{rpm}$, such that the inoculum contained $10^{11}$ cells $/ \mathrm{ml}$. The other bacteria like Azospirillum brasilense and PSB (mixture of Bacillus subtilis and B. megatherium) were cultured in nutrient broth and then multiplied in finely powdered and sterilized charcoal powder. The broth containing $10^{9}$ cells $/ \mathrm{ml}$ was added to $1 / 3$ of the water holding capacity of the carrier.

The seeds of Troyer citrange (Citrus sinensis $\times$ Poncirus trifoliata), the rootstock of citrus, were collected from the citrus germplasm block of the Division of Fruits and Horticultural Technology, IARI and then surface sterilized and kept over wet filter paper in Petri dishes at $28^{\circ} \mathrm{C}$ for germination. After 7 days the seedlings were planted individually in plastic containers containing $5 \mathrm{~kg}$ of mixture of sterilised soil : sand : FYM $(2: 2: 1)$ having electrical conductivity (EC) of $6.35 \mathrm{mS} / \mathrm{m}, \mathrm{pH}$ of $7.92, \mathrm{HCO}_{3}{ }^{-}$content of $1.14 \mathrm{~g} / \mathrm{kg}$ and $\mathrm{Cl}^{-}$content of $5910.75 \mathrm{ppm}$. During planting the seedlings were inoculated with either AM fungus or bacterial species or both @ $5 \mathrm{~g}$ per $\mathrm{kg}$ of potting mixture. In case of Providencia sp., about $20 \mathrm{ml}$ of liquid media containing $10^{11}$ cells per $\mathrm{ml}$ of media was used for each pot. The seedlings were maintained in glasshouse at $27 \pm 1{ }^{\circ} \mathrm{C}$ and humidity of $80-85 \%$. Seedlings were watered on alternate days which had EC of $288 \mu \mathrm{S} / \mathrm{m}, \mathrm{pH}$ of $7.48, \mathrm{HCO}_{3}{ }^{-}$content of 1.0 milliequivalent/ litre and $\mathrm{Cl}^{-}$content of $110.76 \mathrm{ppm}$.

The differential moisture regimes were imposed at 270 days after microbial inoculation. Half of seedlings under each treatment were imposed to ample watered (WW) condition by applying about $750 \mathrm{ml}$ of water at an interval of two days and remaining half were imposed to water stress (WS) by withholding water. Daily soil relative water content was measured using soil moisture meter. Wet point was fixed at $90 \%$ and dry point at $8 \%$. The soil relative water content (RWC) for WW seedlings was monitored at $80 \%$. Different parameters were recorded after harvesting entire plants at 20 days after imposing differential moisture regimes, when WS seedlings recorded visible temporary wilting symptoms. For estimation of antioxidant metabolite, enzymes and reactive oxygen species (ROS), about five grams of leaf samples from each of two seedlings from each of two replications per treatment was taken and immediately washed with double-distilled water and thereafter kept at $-20^{\circ} \mathrm{C}$ deep freeze to prevent the proteolytic activity.

Per cent root colonization was determined using the method as detailed by Philips and Hayman (1970). The presence of fungal hyphae, arbuscles and vesicles were examined by 10X compound microscope. Shoot and root fresh weight was recorded by electronic balance. The samples were then put in the perforated paper bag and kept in hot air oven at $70^{\circ} \mathrm{C}$ until constant dry weight was recorded. The estimation of ROS like $\mathrm{O}_{2}{ }^{-}$and $\mathrm{H}_{2} \mathrm{O}_{2}$ was done as per the methods of Chaitanya and Naithani (1994) and Rao et al. (1996), respectively. The activity of catalase (CAT, EC 1.11.1.6) was estimated as per the method described by Luck (1974). The activity of ascorbate peroxidase (APX, EC 1.11.1.11) was estimated following the method of Nakano and Asada (1981). Guaiacol-peroxidase (G-POD, EC 1.11.1.7) activity was measured according to the method of Thomas et al. (1982). The activity of superoxide dismutase (SOD, EC 1.15.1.1) was assayed according to Beyer and Fridovich (1987) method. Glutathione reductase (GR, EC 1.8.1.7) assay was determined based on the method proposed by Carlberg and Mannervik (1985). Protein concentrations were determined by a modified Lowry method (Hartree 1972) with bovine serum albumin as a standard protein. Total glutathione (GSH + GSSG), was determined in leaf sample according to the method of Grifith (1985) and Smith (1985). For tissue nutrient analyses, ovendried samples were ground, sieved and digested in nitric acid : perchloric acid (9:4). Total nitrogen $(\mathrm{N})$ was determined in samples of $0.5 \mathrm{~g}$ dry weight using the Kjeldahl method. Phosphorous (P) was analysed by a vanadatemolybdate method. The $\mathrm{P}$ transmittance was read at $420 \mathrm{~nm}$. Potassium (K) was determined by Flame photometer (Systronics 128, Ahmedabad) using specific filter and LPG flame. Determination of other foliar nutrients like $\mathrm{Ca}, \mathrm{Mg}, \mathrm{Zn}, \mathrm{Fe}, \mathrm{Cu}$ and Mn was done by the atomic absorption spectrophotometer (GBC-Avanta PM; GBC-Advanta 
Scientific Equipment, Dandenong, Victoria, Australia) using nitrous oxide - acetylene flame. Rhizospheric soil enzyme activity was estimated from 1 gram of soil sample taken from each of two pots from each replication per treatment. Alkaline phosphatase activity was assayed as per the method of Tabatabai and Bremner (1969) and the enzymatic activity was expressed as $\mu \mathrm{g}$ of $\rho$-nitrophenol/g soil dry weight/h. Dehydrogenase activity, expressed as $\mu \mathrm{g}$ of triphenyl formazon/g soil dry weight/day, was assayed as per the method of Casida et al. (1964). Microbial biomass carbon (MBC), expressed as $\mu \mathrm{g} / \mathrm{g}$ soil sample, was estimated following the method of Nunan et al. (1998).

Experiments were laid out in a completely randomised block design with 8 treatments and two replications per treatment. The treatment details are as follows: $\mathrm{T}_{1}=$ Control; $\mathrm{T}_{2}=\mathrm{PSB}, \mathrm{T}_{3}=$ A. brasilense, $\mathrm{T}_{4}=$ Providencia sp. $(\mathrm{AW} 5), \mathrm{T}_{5}=G$. intraradices, $\mathrm{T}_{6}=G$. intraradices and $\mathrm{PSB}$, $\mathrm{T}_{7}=$ G. intraradices and A. brasilense, $\mathrm{T}_{8}=$ G. intraradices and Providencia sp. (AW 5).

The two years experimental data were pooled and then subjected to analysis of variance using statistical analysis software SPSS package (SPSS 11.0) and means were evaluated by Fisher's protected least significant difference (LSD). Differences at $\mathrm{p}<0.05$ were considered significant.

\section{Results and Discussion}

Results revealed 66.67 per cent root colonization was in seedlings co-inoculated with $G$. intraradices and PSB, as compared to other treatments under WS. Colonization was not observed in the roots of non-AM seedlings under WS (Fig. 1). Root colonization by AM fungus and the subsequent benefits derived by a host plant depend initially on the survival of AM fungal spores in soil, which can be reduced by soil moisture deficit. The improved root colonization in the seedlings co-inoculated with AM fungi and PSB, as observed in this study, might be attributed to the improved AM fungal interaction with plant roots due to bacterial inoculation leading to production of active metabolites such as vitamins, amino acids and IAA (Vivas et al. 2003). Thus bacteria might have assisted in the germination of a large number of AM spores leading to rapid fungal establishment in soil.

The seedlings co-inoculated with $G$. intraradices and PSB were significantly superior to control in terms of fresh and dry weights of shoots (360.35 and 304.45\%, respectively) and those of roots (388.60 and 565.84\%, respectively), under WS condition. Similarly, under WW condition, fresh and dry weights of shoots and those of roots were higher by 197.17, 242.63, 219.09 and $165.67 \%$, respectively (Figs 2-5). The growth promoting bacteria, used in the study, particularly PSB were compatible and effective in increasing the benefits of autochthonous AM symbiosis on plant biomass under WS and WW conditions. Thus co-inoculation of PSB and AM fungi might produce growth-stimulating effects that surpassed those of individual inoculations (Galleguillos et al. 2000). Similarly, Barea et al. (2005) concluded that AM fungi and specific rhizosphere bacteria interact to improve plant nutrient (mainly N and P) cycling. Such microbial interactions contribute to plant fitness and soil quality, critical issues for sustainable agricultural development and ecosystem functioning.

Plants suffer ROS induced oxidative damage during WS. The higher accumulation of ROS was recorded in leaves under WS, irrespective of any treatment; however, $\mathrm{O}_{2}{ }^{-}$and $\mathrm{H}_{2} \mathrm{O}_{2}$ content were significantly lower in G. intraradices and PSB co-inoculated Troyer citrange seedlings (29.03 and $22.70 \%$ lesser than control, respectively) (Figs 6 and 7). However, the seedlings subjected to WW condition did not show any significant difference among the treatments for ROS content in leaf. The lower accumulation of ROS in G. intraradices and PSB co-inoculated seedlings might be attributed to efficiency of fungal hyphae for $\mathrm{H}_{2} \mathrm{O}_{2}$ absorption (Wu et al. 2006) and ability of microbial inoculated plants to enhance production of anti-oxidative enzymes 
involved in detoxification by catalyzing the conversion of free $\mathrm{O}_{2}{ }^{-}$to $\mathrm{O}_{2}$ (Huang et al. 2010). Thus anti-oxidative enzymes are the most important components in the scavenging system of ROS under WS condition. Wu and Zou (2009) reported that AM fungi possessed several special genes encoding for antioxidant enzymes, whose expression patterns can regulate the activities of antioxidant enzymes.
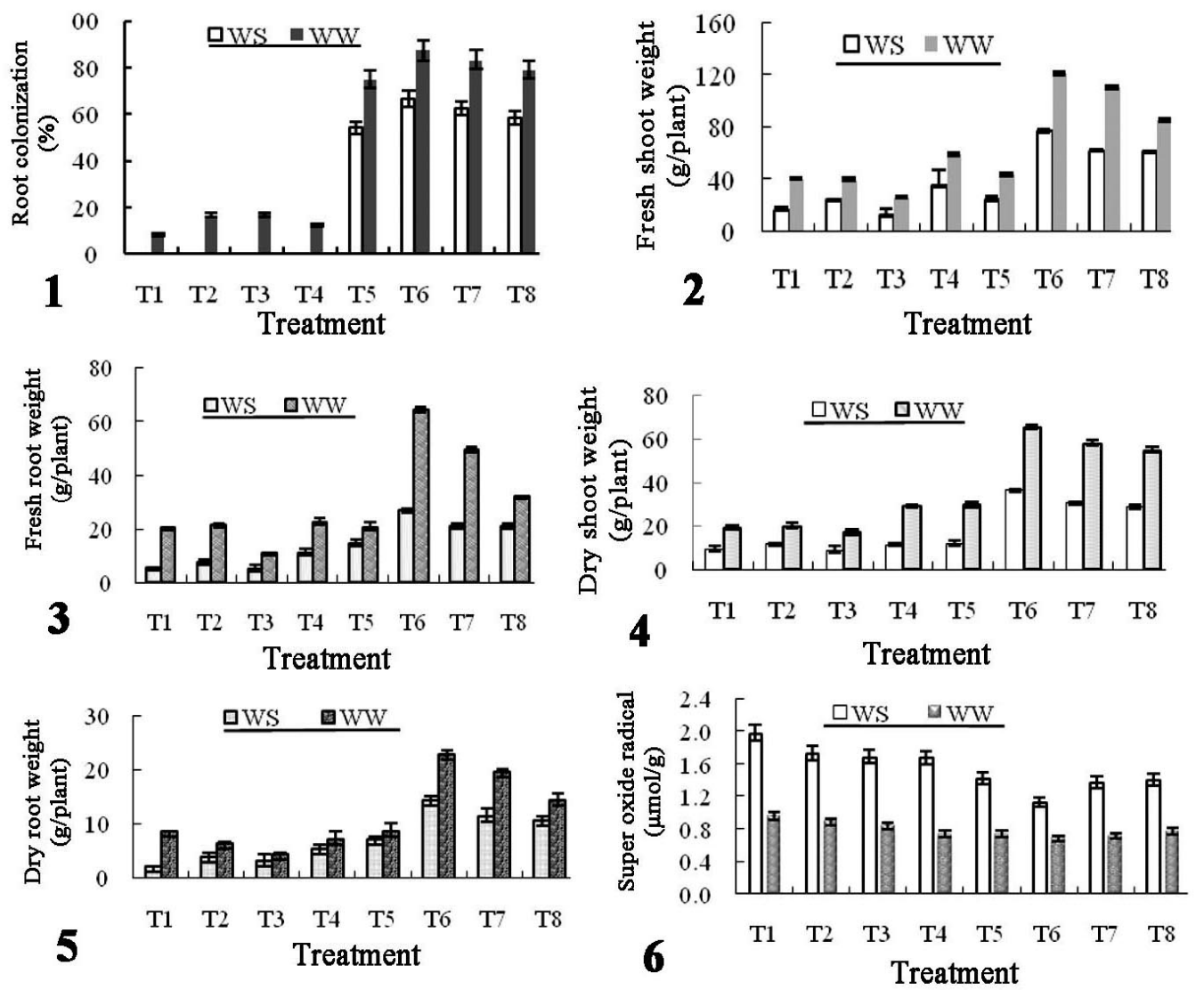

Figs 1-6: 1. Root colonization of Troyer citrange as influenced by G. intraradices and MHB at differential moisture regimes. 2. Fresh shoot weight, 3. Fresh root weight, 4. Dry shoot weight, 5. Dry root weight as in Fig. 1, 6. Super oxide radicals content in leaf of Troyer citrange as influenced by $G$. intraradices and MHB at differential moisture regimes.

The co-inoculation of G. intraradices and PSB showed enhanced activity of CAT (46.91 and 53.58\%), APX (45.94 and 46.85\%), G-POD (28.88 and 27.77\%), GR (73.74 and 73.24\%) and SOD (39.90\%) in leaves, as compared to control, under WS (Figs 8-12). Thus PSB might had stimulated the activity of intraradical mycelium and development of extraradical mycelium from G. intraradices resulting in increased association of AM fungus with plant roots, thereby enhancing the activity of antioxidant enzymes in AM plants subjected to WS. The co-inoculation of G. intraradices and PSB significantly increased total glutathione content in leaf by 24.59 and 22.64 per cent more than control under WS and WW condition, respectively (Fig. 13). Thus PSB might have synergistic interaction with AM fungus for increasing the production of total glutathione in leaves, implying that ascorbate-glutathione cycle would efficiently work in 
microbial inoculated seedlings. the present results are in agreement with the findings of Kaya et al. (2009) who reported that AM plants had potential to accumulate antioxidants to counteract ROS under any environmental stress.
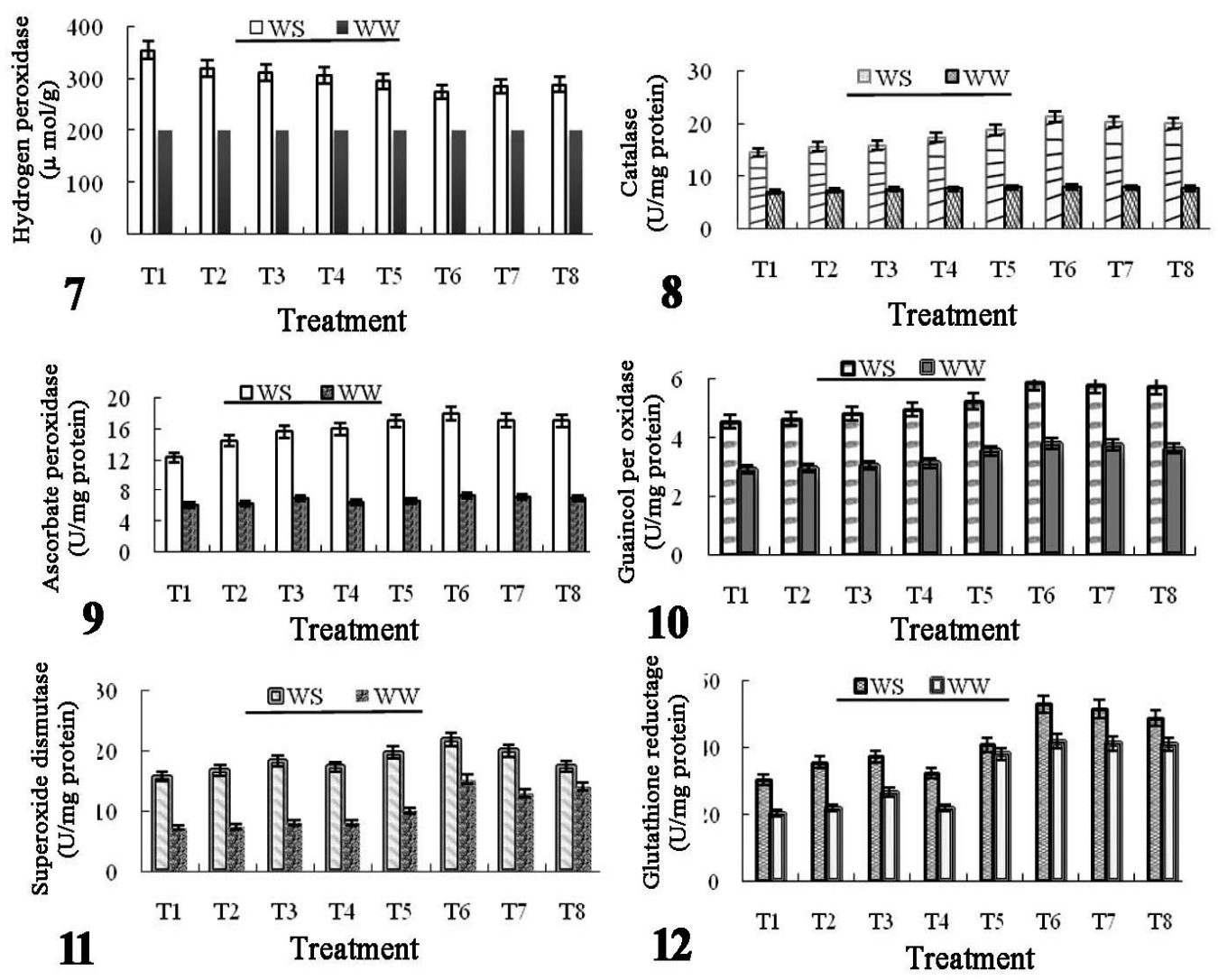

Figs 7-12: 7. Hydrogen peroxide content in leaf of Troyer citrange as influenced by G. intraradices and MHB at differential moisture regimes. 8. Catalase activity. 9. Ascorbate peroxidase activity.10. Guaiacol peroxidase activity. 11. Superoxide dismutase activity. 12. Glutathione reductase activity as in Fig. 7.

The co-inoculation of $G$. intraradices and A. brasilense resulted in increased leaf $\mathrm{N}$ content by 73.27 and 44.77 per cent under WS and WW conditions, respectively, over control (Fig. 14). The maximum foliar N content in seedlings co-inoculated with $G$. intraradices and $A$. brasilense might be attributed to increase in $\mathrm{N}$-assimilating enzymes, such as nitrate reductase in the shoots of AM fungal colonised plants (Caravaca et al. 2005). The leaf P, K, Ca and Mg content was significantly increased by $G$. intraradices and PSB co-inoculation at any moisture regime (Figs 15-18). The application of G. intraradices along with PSB, A. brasilense or Providencia sp. (AW 5) resulted in significantly high level of leaf micronutrient content, as compared to control (Figs. 19-22). The maximum level of $\mathrm{P}$ in leaves of seedlings co-inoculated with $G$. intraradices and PSB might be due to release of phosphate ions from sparingly soluble inorganic and organic $\mathrm{P}$ compounds in soil, thereby contributing increased soil phosphate pool available for the extraradical AM fungal hyphae to pass on to the plant. The enhanced acquisition of other mineral nutrients $(\mathrm{K}, \mathrm{Ca}, \mathrm{Mg}, \mathrm{Fe}, \mathrm{Cu}, \mathrm{Mn}$ and $\mathrm{Zn})$ in leaves due to co-inoculation of G. intraradices and 
PSB could be attributed to the greater absorption of the surface area provided by extensive fungal hyphae (Navarro et al. 2011).
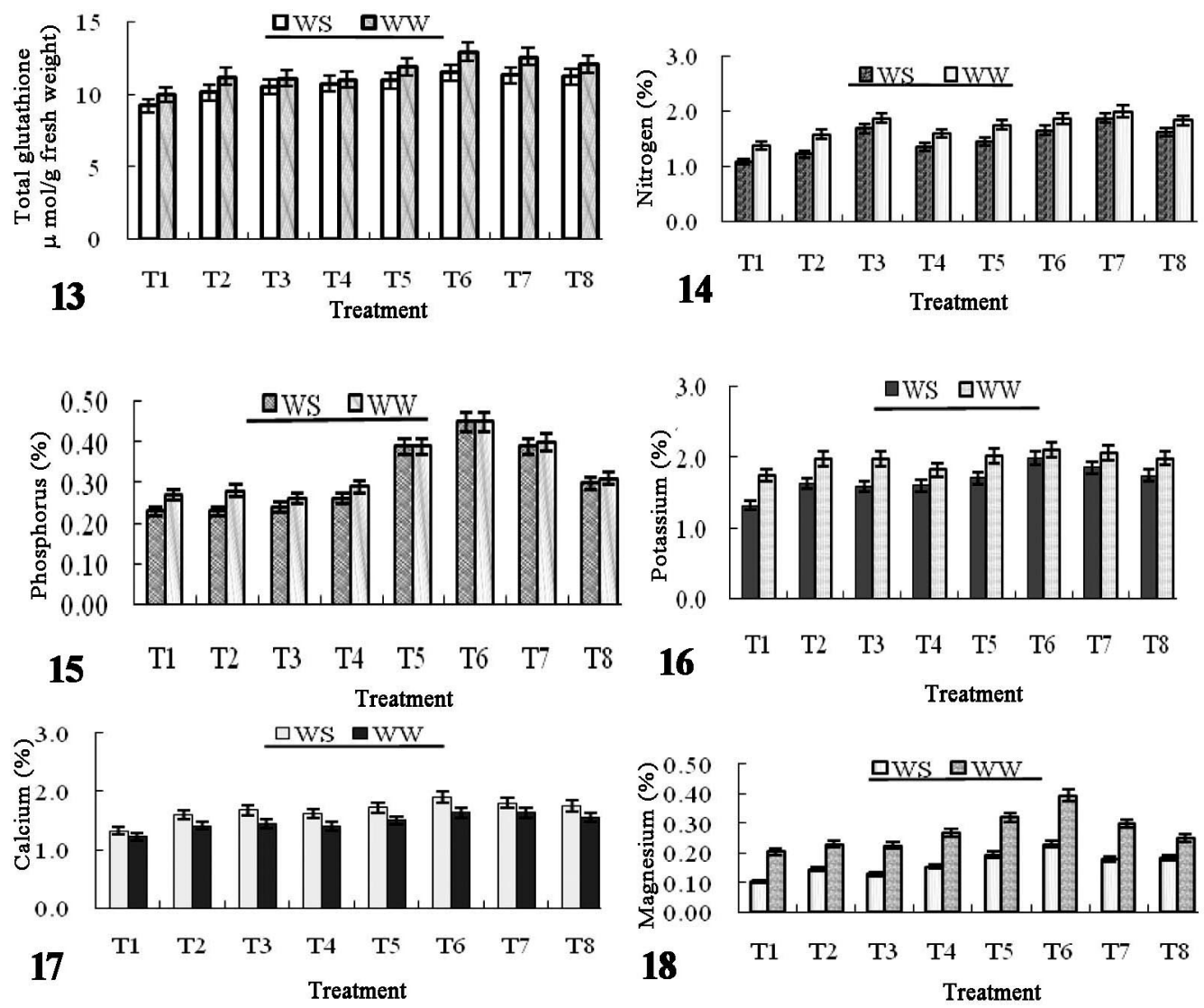

Figs 13-18: 13. Total glutathione content in leaf of Troyer citrange as influenced by $G$. intraradices and MHB at differential moisture regimes. 14. Leaf $\mathrm{N}$ content. 15. Leaf $\mathrm{P}$ content. 16. Leaf $\mathrm{K}$ content. 17. Leaf Ca content. 18. Leaf Mg content as in Fig. 13.

Soil enzyme activity measurement may be useful for gaining a better understanding of the nature of the perturbations caused to ecosystem function after microbial inoculations. The adverse effect of WS was noticed on soil enzyme activity among different treatments. However, activities of dehydrogenase and alkaline phosphatase were 76.84 and 87.08 per cent, respectively more and microbial biomass carbon was 173.15 per cent more in rhizospheric soil of seedlings co-inoculated with G. intraradices and PSB, as compared to control (Figs 23-25). The maximum dehydrogenase and alkaline phosphatase activities and microbial biomass carbon in rhizosphere of seedlings coinoculated with $G$. intraradices and PSB might be attributed to increase in the rhizosphere microbial population as a consequence of the inoculation (Aseri and Tarafdar 2006) leading to increase in carbon and nutrient leakage from roots. 

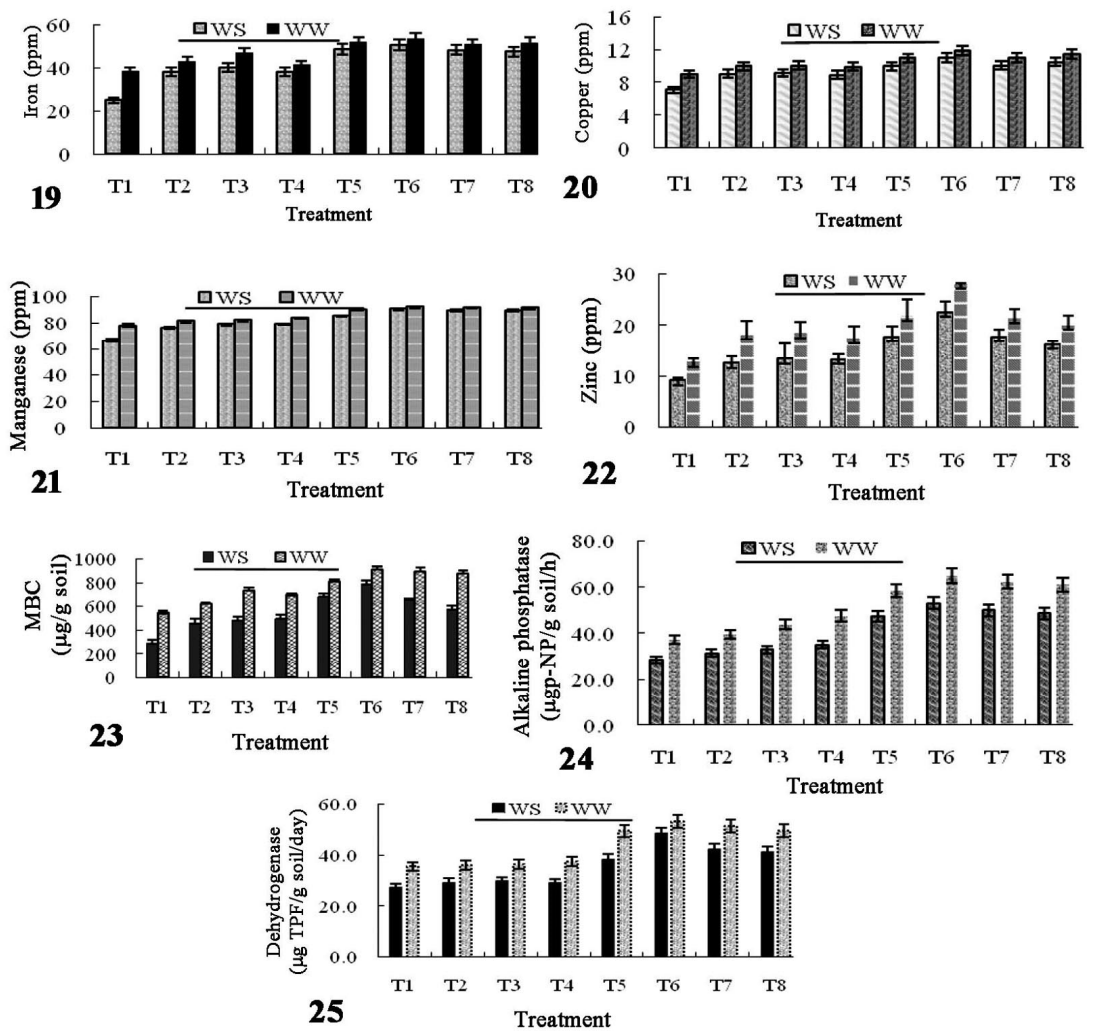

Figs 19-25: 19. Leaf Fe content of Troyer citrange as influenced by G. intraradices and MHB at differential moisture regimes. 20. Leaf $\mathrm{Cu}$ content. 21. Leaf $\mathrm{Mn}$ content. 22. Leaf $\mathrm{Zn}$ content. 23. Microbial biomass carbon in rhizosphere. 24. Soil Alkaline phosphatase activity. 25. Soil Dehydrogenase activity as in Fig. 19.

From the above results, it may be concluded that co-inoculation of $G$. intraradices and PSB exhibits superiority in respect of physiological and biochemical conditions of seedlings, as compared to single inoculation or other microbial co-inoculation including control under WS. Thus, Troyer citrange could be co-inoculated with $G$. intraradices and PSB during propagation in nursery for healthy growth of the seedlings, thereby preponding the budding time and subsequent establishment of budded plants under dry environment.

\section{References}

Aseri GK and Tarafdar JC 2006. Fluorescein diacetate: a potential biological indicator for arid soils. Arid Land Res. Manage. 20: 87-99.

Barea JM, Azcón R and Azcón-Aguilar C 2005. Interactions between mycorrhizal fungi and bacteria to improve plant nutrient cycling and soil structure. In: Varma A, Buscot F (Eds.), Microorganisms in Soils: Roles in Genesis and Functions, Soil Biology, Vol. 3, Springer, Berlin, Heidelberg.

Beyer WF and Fridovich I 1987. Assaying for superoxide dismutase activity: Some large consequences of minor changes in conditions. Analytical Biochem. 161: 559-66.

Caravaca F, Alguacil MM, Hernande JA and Roldan A 2005. Involvement of antioxidant enzyme and nitrate reductase activities during water stress and recovery of mycorrhizal Myrtus communis and Phillyrea angustifolia plants. Plant Science 169: 191-7. 
Carlberg I and Mannervik B 1985. Glutathione reductase. Methods in Enzymology 113: 484-90.

Casida L, Johnson J and Klein D 1964. Soil dehydrogenase activity. Soil Science 98: 371-6.

Chaitanya KSK and Naithani SC 1994. Role of superoxide, lipid peroxidation and superoxide dismutase in membrane perturbations during loss of viability in seeds of Shorea robusta Gaertn. f. New Phytol. 126: 623-7.

Galleguillos C, Aguirre C, Barea JM and Azcon R 2000. Growth promoting effect of two Sinorhizobium meliloti strains (a wild type and its genetically modified derivative) on a non-legume plant species in specific interaction with two arbuscular mycorrhizal fungi. Plant Science 159: 57-63.

Grifith OW 1985. Glutathione and glutathione disulphide. In: Methods of enzymatic analysis, Bergmeyer HU (Ed), pp. 521-9. Verlagsgesellschaft mbH, Weinheim, Florida.

Hartree EE 1972. Determination of protein: A modification of the Lowry method that gives a linear photometric response. Anal. Biochem. 48: $422-7$.

Huang Z, Chao-xing H, Zhong-qun H, Zhi-rong Z and Zhi-bin Z 2010. The effects of arbuscular mycorrhizal fungi on reactive oxy-radical scavenging system of tomato under salt tolerance. Agricul. Sci. China 9(8): $1150-59$

Kaya C, Ashraf M, Sonmez O, Aydemir S, Tuna AL and Cullu MA 2009. The influence of arbuscular mycorrhizal colonisation on key growth parameters and fruit yield of pepper plants grown at high salinity. Scientia Horticult.121:1-6.

Luck H 1974. Catalase. In: Methods of Enzymatic analysis, Bergmeyer J and Grabi M (Eds), pp. 885-90. Academic Press, Vol. II, New York.

Nakano Y and Asada K 1981. Hydrogen peroxide is scavenged by ascorbate-specific peroxidase in spinach chloroplasts. Plant and Cell Physiology 22(5): 867-80.

Navarro GA, Del P, Banon AS, Morte A and Sanchez-Blanco MJ 2011. Effects of nursery pre-conditioning through mycorrhizal inoculation and drought in Arbutus unedo L. plants. Mycorrhiza 21: 53-64.

Nunan N, Morgan MA and Herlihy M 1998. Ultraviolet absorbance $(280 \mathrm{~nm})$ of compounds released from soil during chloroform fumigation as an estimate of the microbial biomass. Soil Biol. Biochem. 30:1599-603.

Philips JM and Hayman DS 1970. Improved procedure for clearing roots and staining parasitic and vesiculararbuscular mycorrhizal fungi for rapid assessment of infection. Transactions in Bazilian Mycol. Soc. 55: 158-61.

Rana A, Saharan B, Kabi SR, Prasanna R and Nain L 2011. Providencia, a PGPR with biocontrol potential elicits defense enzymes in wheat. Ann. Pl. Protec. Sci. 19(1): 138-41.

Rao MV, Paliyath G and Ormrod DP 1996. Ultraviolet-B- and ozone-induced biochemical changes in antioxidant enzymes of Arabidopsis thaliana. Plant Physiol. 110: 125-36.

Smith IK 1985. Stimulation of glutathione synthesis in photorespiring by catalase inhibitors. Plant Physiol. 79: $1044-47$.

Tabatabai MA and Brenmer JA 1969. Use of p-nitrophenyl phosphate for assay of soil phosphatase activity. Soil Biol. Biochem. 1:301-07.

Thomas RL, Jen JJ and Morr CV 1982. Changes in soluble and bound peroxidase, IAA oxidase during tomato fruit development. J. Food Sci. 47(1): 158-61.

Vivas A, Azcon R, Biro B, Barea JM and Ruiz-Lozano JM 2003. Influence of bacterial strains isolated from lead-polluted soil and their interactions with arbuscular mycorrhizae on the growth of Trifolium pratense L. under lead toxicity. Can. J. Microbiol. 49: 577-88.

Wu QS, Xia RX and Zou YN 2006. Reactive oxygen metabolism in mycorrhizal and non-mycorrhizal citrus (Poncirus trifoliata) seedlings subjected to water stress. Journal of Plant Physiology 163:1101-10.

Wu QS and Zou YN 2009. Mycorrhiza has a direct effect on reactive oxygen metabolism of drought-stressed citrus. Plant Soil Environ. 55(10): 436-42. 